\title{
Biomass:polystyrene co-pyrolysis coupled with metal-modified zeolite catalysis for liquid fuel and chemical production
}

\author{
Andrew C. Dyer ${ }^{1} \cdot$ Mohamad A. Nahil $^{1} \cdot$ Paul T. Williams $^{1}$ D
}

Received: 9 June 2021 / Accepted: 21 November 2021 / Published online: 4 January 2022

(c) The Author(s) 2022

\begin{abstract}
Biomass and waste polystyrene plastic (ratio 1:1) were co-pyrolysed followed by catalysis in a two-stage fixed bed reactor system to produce upgraded bio-oils for production of liquid fuel and aromatic chemicals. The catalysts investigated were ZSM-5 impregnated with different metals, $\mathrm{Ga}, \mathrm{Co}, \mathrm{Cu}, \mathrm{Fe}$ and $\mathrm{Ni}$ to determine their influence on bio-oil upgrading. The results showed that the different added metals had a different impact on the yield and composition of the product oils and gases. Deoxygenation of the bio-oils was mainly via formation of $\mathrm{CO}_{2}$ and $\mathrm{CO}$ via decarboxylation and decarbonylation with the Ni-ZSM-5 and Co-ZSM-5 catalysts whereas higher water yield and lower $\mathrm{CO}_{2}$ and CO was obtained with the ZSM-5, Ga-ZSM-5, Cu-ZSM-5 and Fe-ZSM-5 catalysts suggesting hydrodeoxygenation was dominant. Compared to the unmodified ZSM-5, the yield of single-ring aromatic compounds in the product oil was increased for the Co-ZSM-5, Cu-ZSM-5, Fe-ZSM-5 and Ni-ZSM-5 catalysts. However, for the Ga-ZSM-5 catalyst, single-ring aromatic compounds were reduced, but the highest yield of polycyclic aromatic hydrocarbons was produced. A higher biomass to polystyrene ratio (4:1) resulted in a markedly lower oil yield with a consequent increased yield of gas.
\end{abstract}

Keywords Biomass $\cdot$ Waste plastic:zeolite $\cdot$ Catalyst $\cdot$ Bio-oil

\section{Introduction}

Lignocellulosic biomass waste includes agricultural residues, forestry waste and municipal solid waste and represents a huge potential global biomass resource. For example, it is estimated that 4.6 billion tonnes of agricultural residues are produced worldwide each year [1]. Such available tonnages of biomass could be used to produce fuels as a renewable alternative to fossil fuels, thereby mitigating the environmental and climate change impacts of fossil fuel resources. One route for utilisation of lignocellulosic biomass for fuel production is via thermochemical conversion via the pyrolysis process. Pyrolysis of biomass involves heating the biomass to moderate temperature $\left(\sim 500{ }^{\circ} \mathrm{C}\right)$ in the absence of air to produce a bio-oil, char and gas product. The production of a liquid bio-oil produced from lignocellulosic biomass has been promoted as a route to alternative transport fuels [2]. However, the characteristics of the product

Paul T. Williams

p.t.williams@leeds.ac.uk

1 School of Chemical and Process Engineering, University of Leeds, Leeds LS2 9JT, UK bio-oil are not suitable for use directly as a transport fuel or even as a petroleum refinery feedstock since it is chemically very complex containing many different functional groups, it has a high oxygen and moisture content and a tendency to polymerise over a period of time [2]. Consequently, to overcome these issues there has been extensive research into upgrading the bio-oil by removing the oxygen to produce a hydrocarbon-rich oil suitable for petrochemical feedstock or direct use as a liquid fuel. Routes to removing oxygen from the bio-oil centre on hydrotreatment involving added hydrogen with processing at high pressure (10-20 MPa) [3] or catalytic deoxygenation using zeolite catalysts at atmospheric pressure and moderate temperature $\left(\sim 500^{\circ} \mathrm{C}\right)[4,5]$.

Such processes have some disadvantages, for example, hydrotreatment involves addition of expensive hydrogen gas, and zeolite catalysis removes the oxygen as carbon oxides and water, thereby also removing some of the carbon and hydrogen content. A further drawback of zeolite catalysts, particularly ZSM- 5 is the propensity to form coke on the catalyst surface, linked to the hydrogen deficient and oxygenrich composition of lignocellulosic biomass [6]. Another recent line of research has sought to introduce a hydrogen donor into the process by co-processing the lignocellulosic 
waste biomass with a hydrogen-rich feedstock such as waste plastics thereby enhancing the effective $\mathrm{H}: \mathrm{C}$ ratio [7-9]. The most common plastics found in municipal solid waste are polyethylene, polypropylene, polyethylene terephthalate and polystyrene [10]. The co-pyrolysis of biomass and waste plastics has been shown to reduced the oxygen content and increase the aromatic content of the product bio-oil [7].

Polystyrene is an aromatic hydrocarbon polymer and represents a high hydrogen content waste plastic which is produced in large quantities. The world production of polystyrene is estimated to be approximately 25 million tonnes per year and polystyrene waste generation estimated at 17 million tonnes per year [11]. In Europe, about 53\% of polystyrene production is rigid and $47 \%$ expanded polystyrene [12]. With increasing societal concern related to plastic waste in the environment, recycling processes for plastic waste are under development worldwide. Of particular interest are recycling processes for waste plastics that produce a high value product, such as liquid fuels, and chemicals $[10,13$, 14].

Co-pyrolysis of lignocellulosic waste biomass and waste plastics has been reported and reviewed [15-17]. In particular, there has been research into the improvement of bio-oil properties by the addition of polystyrene [18-21]. Although improvements in the product oil have been reported for copyrolysis of biomass with plastics, the quality is not sufficient for direct use as a fuel and therefore addition of a catalyst, mainly zeolites, has been investigated [22, 23]. In particular, there has also been research into the co-pyrolysis of biomass and polystyrene coupled with zeolite catalysis [24-28]. For example, Kumar and Srinivas [27] used a fixed bed slow co-pyrolysis-catalytic reactor for the production of liquid fuels from biomass and polystyrene using spent FCC zeolite catalyst. They reported that increased addition of polystyrene in the biomass produced an upgraded bio-oil with a high content of styrene, ethylbenzene, styrene oligomers, benzene derivatives and polycyclic aromatic compounds. Our previous work [28] used a two-stage fixed bed pyrolysis-catalytic reactor to investigate the co-pyrolysis of biomass and plastics, including polystyrene with a ZSM-5 zeolite catalyst. The product upgraded bio-oil contained mainly $\mathrm{C}_{5}-\mathrm{C}_{12}$ fuel range hydrocarbons and with a high content of 1-4 ring aromatic compounds.

The process of zeolite ZSM-5 bio-oil upgrading involves dehydration and dehydrogenation reactions which decrease hydrogen content and also promotes catalyst coke formation. Therefore, to further enhance the zeolite catalytic cracking process and reduce coke formation, for co-pyrolysis of biomass and polystyrene, the zeolite catalyst has been modified with metals in an attempt to improve the catalyst properties and in turn improve quality of the upgraded oil. Razzaq et al. [6] used a two-stage fixed bed reactor to study the co-pyrolysis of wheat straw and polystyrene coupled with a catalyst reactor. The catalysts investigated were zeolite HZSM-5 and metal modified HZSM-5 impregnated with $\mathrm{Co}, \mathrm{Ni}, \mathrm{Zn}$ and Fe. They reported that the metal-modified ZSM-5 catalysts increased oil yield and single-ring aromatic content of the product oil compared to unmodified HZSM- 5 catalyst. The role of the metal addition to ZSM-5 catalysts is reported to affect the Lewis and Brønsted acid sites and surface physical properties of the catalyst $[29,30]$. The consequence is a reduction in the rate of catalyst coke formation and thereby improved hydrocarbon yield. The addition of metals to ZSM-5 zeolite is also reported to be selective towards the formation of increased single-ring aromatic compounds [6].

In this paper, we report on the two-stage co-pyrolysis of waste biomass and waste polystyrene directly coupled with a catalyst reactor containing metal-modified $(\mathrm{Ga}, \mathrm{Co}, \mathrm{Cu}$, $\mathrm{Fe}, \mathrm{Ni}$ ) ZSM-5 zeolite catalysts. The aim of the work was to improve the deoxygenation of the product bio-oil and increase the yield of aromatic compounds in relation to the production of higher value liquid fuels and aromatic chemicals. The product yield and composition of the gases and product oils are reported in relation to the different metalmodified ZSM-5 catalysts. Biomass/plastics co-pyrolysis studies have been carried out before and there is much work on the influence of metal promoters added to zeolite ZSM-5 catalysts to upgrade biomass pyrolysis oils. However, the novelty of this work lies in the detailed study of the product oils and gases in relation to the combination of both biomass/polystyrene co-pyrolysis and also metal-promoted zeolite ZSM-5 catalyst with the specific aim of upgrading the product oils for the production of liquid fuels and aromatic hydrocarbons.

\section{Materials and methods}

\section{Feedstock and catalyst}

The feedstock materials used for co-pyrolysis were waste biomass and real-world waste polystyrene. The biomass was obtained as wood pellets produced as compressed sawdust pellets from waste wood and supplied by Liverpool Wood Pellets Ltd, Liverpool, UK. The pellets were milled and sieved to a size range between 1.0 and $2.8 \mathrm{~mm}$. The waste polystyrene plastic was in the form of recyclate waste plastic pellets $(2 \mathrm{~mm} \times 2 \mathrm{~mm}$ ) supplied by Regain Polymers Limited, Castleford, UK. Table 1 shows the proximate and elemental analysis of the waste biomass and polystyrene.

The thermal decomposition profiles of the biomass, polystyrene and a mixture of biomass and polystyrene were investigated using thermogravimetric analysis (TGA). The system used was a TA instruments, Q600 thermogravimetric analyser. The sample of biomass was 
Table 1 Proximate and elemental analysis of the biomass and polystyrene wastes

\begin{tabular}{lrc}
\hline & Biomass & Polystyrene \\
\hline Proximate analysis (wt.\%) & & \\
Moisture (ar) & 7.8 & 0.0 \\
Volatiles (daf) & 93.3 & 100.0 \\
Ash (d) & 0.3 & 1.6 \\
Fixed carbon (daf) & 6.7 & 0.0 \\
Elemental analysis (wt.\%) (daf) & & \\
Carbon & 50.1 & 87.8 \\
Hydrogen & 5.4 & 9.5 \\
Oxygen & 48.6 & 0.0 \\
Nitrogen & 0.1 & 0.0 \\
\hline
\end{tabular}

ar as received, $d$ dry, daf dry ash free

ground to fine particle size and the polystyrene ground using a cryo-mill and the samples mixed intimately for the TGA analysis.

The co-pyrolysis of biomass and polystyrene coupled with catalysis used a zeolite ZSM-5 catalyst supplied by Nankai University Catalyst Co. Ltd, Tianjin, PR China. The properties of the ZSM-5 were: surface area, 282 $\mathrm{m}^{2} \mathrm{~g}^{-1}$; micropore volume, $0.26 \mathrm{~cm}^{3} \mathrm{~g}^{-1}$ and $\mathrm{Si}$ :Al ratio, $38: 1$. The catalyst was modified by wet impregnation to produce Ga-ZSM-5, Co-ZSM-5, Cu-ZSM-5, Fe-ZSM-5 and Ni-ZSM-5 at 5 wt.\% metal loading. The metal salts used were gallium (III) nitrate nonahydrate, cobalt (II) nitrate hexahydrate, copper (II) nitrate trihydrate, iron (III) nitrate nonahydrate and nickel (II) nitrate hexahydrate obtained from Sigma-Aldrich UK Ltd. Each metal salt was added into deionized water and heated to $30^{\circ} \mathrm{C}$ to aid dissolution. The solid ZSM-5 was added to the metal solution and the mixture heated slowly from ambient to a temperature of $80{ }^{\circ} \mathrm{C}$ to produce a thick slurry. The slurry was dried at $110{ }^{\circ} \mathrm{C}$ for $10 \mathrm{~h}$ and then calcined at $500{ }^{\circ} \mathrm{C}$ for $5 \mathrm{~h}$. Prior to use, the catalysts were reduced in hydrogen $\left(5\right.$ vol. $\% \mathrm{H}_{2}, 95$ vol. $\left.\% \mathrm{~N}_{2}\right)$ at $800{ }^{\circ} \mathrm{C}$ for $1 \mathrm{~h}$.

The surface area and porosity of the freshly prepared metal-ZSM-5 catalysts was determined by Brunauer, Emmet and Teller (BET) nitrogen adsorption analysis using a NOVA 2200e instrument. The results presented in Table 2 show that the addition of the metal to the ZSM-5 reduced the surface area of the catalysts by small but significant amounts, for example, the Co-ZSM-5 catalyst had a reduction in surface area of $6.4 \%$ and for the Ga-ZSM-5 catalyst, it was reduced by $4.6 \%$. The introduction of the metals lead to blocking of pores and consequent reduction of pore volume and surface area (Table 2).
Table 2 BET surface area and pore volume of ZSM-5 and metalimpregnated ZSM-5 catalysts

\begin{tabular}{lll}
\hline Sample & $\begin{array}{l}\text { Specific surface area } \\
\left(\mathrm{m}^{2} \mathrm{~g}^{-1}\right)\end{array}$ & $\begin{array}{l}\text { Pore volume } \\
\left(\mathrm{cm}^{3} \mathrm{~g}^{-1}\right)\end{array}$ \\
\hline ZSM-5 & 282 & 0.26 \\
$\mathrm{Cu}-Z S M-5$ & 268 & 0.25 \\
Co-ZSM-5 & 264 & 0.23 \\
Ni-ZSM-5 & 275 & 0.25 \\
Ga-ZSM-5 & 269 & 0.23 \\
Fe-ZSM-5 & 278 & 0.25 \\
\hline
\end{tabular}

\section{Experimental reactor system}

The reactor system consisted of a $\mathrm{N}_{2}$ purged, two-stage reactor system with pyrolysis of the biomass and polystyrene in the first-stage pyrolysis reactor, followed by on-line catalytic upgrading of the product pyrolysis vapours and gases in a separate catalyst reactor comprising the second stage. A schematic diagram of the reactor system is shown in Fig. 1. The reactor was vertical with a $40 \mathrm{~mm}$ diameter and $470 \mathrm{~mm}$ height and heated by two separately controlled and temperature-monitored electrically heated furnaces, providing two separate heating zones. The biomass $(1.0 \mathrm{~g})$ and polystyrene $(1.0 \mathrm{~g})$ were mixed together to produce $2.0 \mathrm{~g}$ of feedstock and placed in a stainless steel crucible within the pyrolysis reactor. The metal-ZSM-5 zeolite catalyst $(4.0 \mathrm{~g})$ was placed on a support bed of a stainless steel mesh and quartz wool

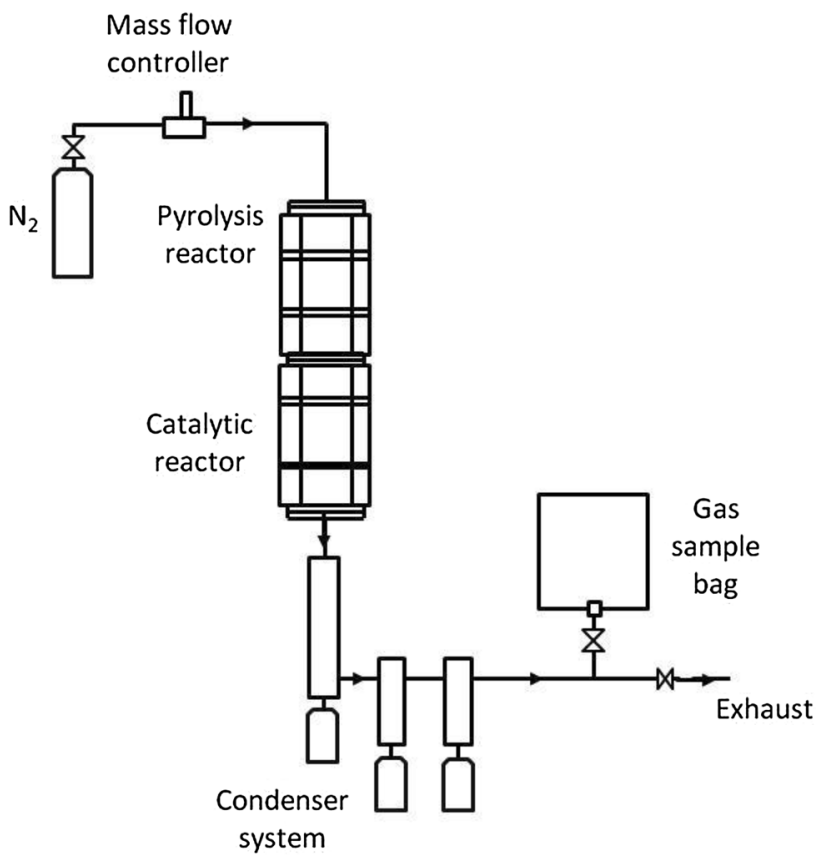

Fig. 1 Schematic diagram of the two-stage fixed bed pyrolysis-catalysis reactor 
support to provide a fixed bed of catalyst. The experimental procedure consisted of pre-heating the catalyst bed to $500{ }^{\circ} \mathrm{C}$ followed by slow pyrolysis heating of the biomass and polystyrene in the pyrolysis reactor to a final temperature of $500{ }^{\circ} \mathrm{C}$ with a heating rate of $10^{\circ} \mathrm{C} \mathrm{min}^{-1}$ and held at $500{ }^{\circ} \mathrm{C}$ for $20 \mathrm{~min}$. The product oils were condensed in a three-stage dry-ice condensation system followed by collection of the product gases in a $25 \mathrm{~L}$ Tedlar gas sample bag. The residual char was collected after each experiment.

\section{Gas analysis}

The product gases collected in the gas sample bag were analysed by packed column gas chromatography, using three separate Varian 3380 gas chromatographs (GC). One GC measured $\mathrm{H}_{2}, \mathrm{O}_{2}, \mathrm{~N}_{2}$ and $\mathrm{CO}$ using a 60-80 mesh molecular sieve column, Ar carrier gas and thermal conductivity detector (TCD). A second GC measured $\mathrm{CO}_{2}$ with a HayeSep 60-80 mesh column, Ar carrier gas and TCD. The third GC determined C-C hydrocarbons with a Hysesp, 80-100 mesh column and flame ionisation detector (FID). The mass of gas was calculated from the gas concentrations, recorded gas flow rate and the ideal gas law.

\section{Bio-oil analysis}

The product upgraded bio-oil was collected from the condenser system using a fixed volume of methanol solvent and stored in borosilicate glass containers. The bio-oil would contain water derived from the biomass, and therefore, the waste content of the bio-oil was determined by Karl-Fischer volumetric titration. For analysis of the bio-oils, the water was removed from the sample prior to analysis using a drying column packed with anhydrous sodium sulphate. The dried bio-oil sample was analysed using coupled gas chromatography-mass spectrometry (GC-MS) (Varian CP-3800 GC-Varian Saturn 2200 MS). The GC column was a $30 \mathrm{~m} \times 0.25 \mathrm{~mm}$ VF-5 MS capillary column. Identification and quantification of the bio-oil compounds used the National Institute of Science and Technology (NIST) compound library and the set of $>40$ standard aromatic and oxygenated compounds.

\section{Results and discussion}

\section{Thermal decomposition of the biomass and polystyrene}

Thermogravimetric analysis of the biomass, polystyrene and the 1:1 mixture of the two components was undertaken to determine the thermal degradation profiles of the samples. Figure 2 shows the thermal decomposition weigh loss
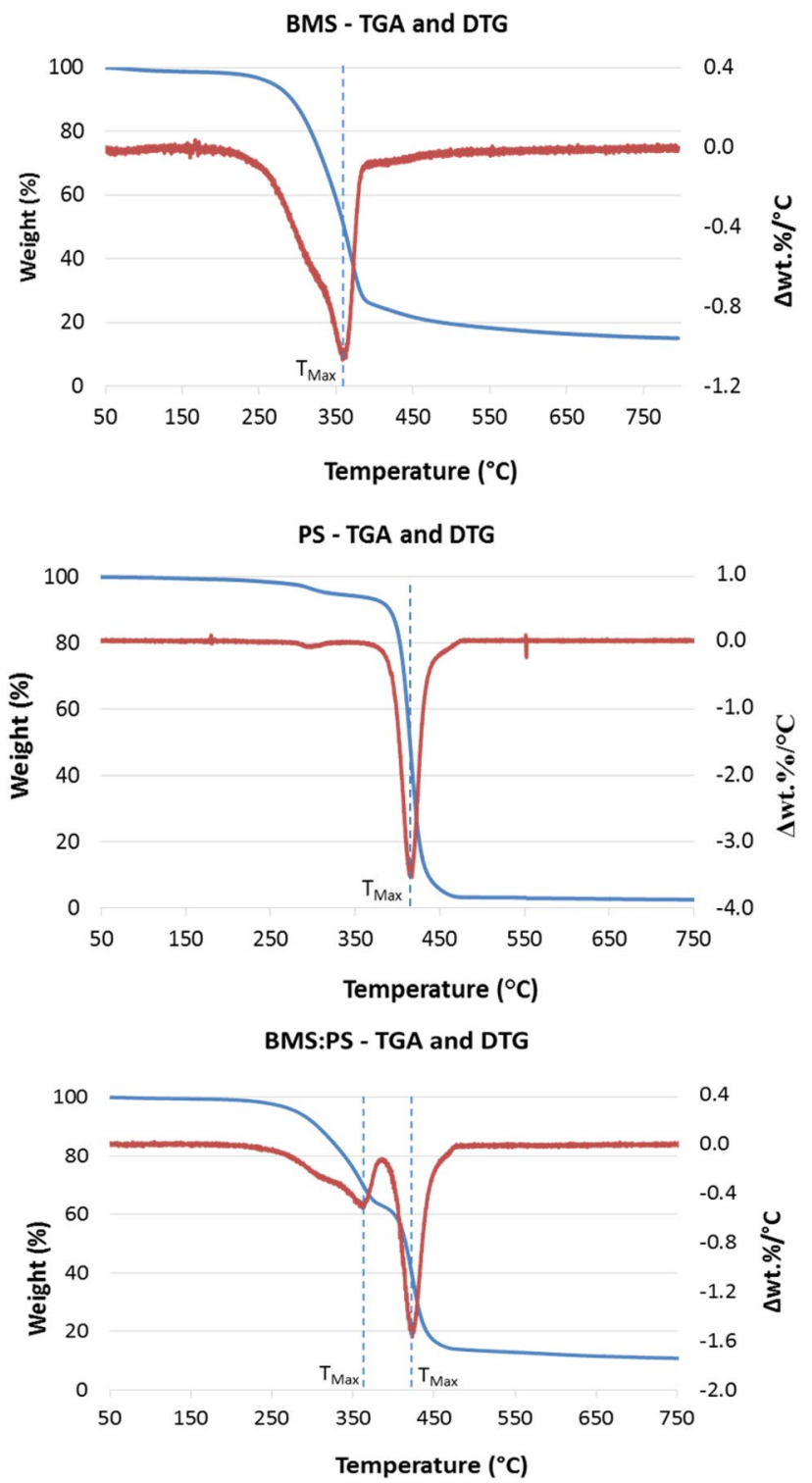

Fig. 2 Thermal decomposition (TGA) and differential weight loss profiles of biomass, polystyrene and a mixture of biomass and polystyrene (1:1)

(TGA) and the rate of weight loss (DTG) of the samples and Table 3 shows the onset temperature of degradation $\left(\mathrm{T}_{\text {onset }}\right)$, the maximum $\left(\mathrm{T}_{\max }\right)$ and end point of weight loss $\left(\mathrm{T}_{\text {end }}\right)$. The thermal decomposition of biomass is dependent on the proportion of the major bio-polymer cellulose, hemicellulose and lignin which comprise the biomass composition [15, 31]. Hemicellulose decomposes over a lower temperature range, $\left(220-380{ }^{\circ} \mathrm{C}\right)$, cellulose over the range $280-440{ }^{\circ} \mathrm{C}$ and lignin over the temperature range of $250-500{ }^{\circ} \mathrm{C}$ [32]. For the particular biomass wood waste used in this work, the thermal degradation was over the temperature range of 201-394 ${ }^{\circ} \mathrm{C}$ with the maximum weight loss at $360{ }^{\circ} \mathrm{C}$. It is clear from Fig. 2 and Table 3 that the polystyrene waste 
Table 3 Temperatures of devolatilisation for the pyrolysis of biomass, polystyrene and mixed biomass:polystyrene (1:1) using thermogravimetric analysis (TGA and DTG)

\begin{tabular}{llll}
\hline & \multicolumn{3}{l}{$\begin{array}{l}\text { Temperature of devolatilisa- } \\
\text { tion }\left({ }^{\circ} \mathrm{C}\right)\end{array}$} \\
\cline { 2 - 4 } & $\mathrm{T}_{\text {onset }}$ & $\mathrm{T}_{\max }$ & $\mathrm{T}_{\text {end }}$ \\
\hline Biomass & 201 & 360 & 394 \\
Polystyrene & 360 & 416 & 478 \\
BMS:PS mixture (biomass) & 224 & 363 & 384 \\
BMS:PS mixture (polystyrene) & 384 & 423 & 478 \\
\hline
\end{tabular}

decomposes at a higher temperature range of $360-478{ }^{\circ} \mathrm{C}$ with a peak decomposition at $416{ }^{\circ} \mathrm{C}$. Table 3 suggests that co-pyrolysis of the mixture of biomass and polystyrene in the TGA produced a slight increase in the peak weight loss $\left(\mathrm{T}_{\max }\right)$ for both the biomass and polystyrene component of the feedstock, increasing from $360{ }^{\circ} \mathrm{C}$ to $363{ }^{\circ} \mathrm{C}$ and $416{ }^{\circ} \mathrm{C}$ to $423{ }^{\circ} \mathrm{C}$, respectively.

The interaction of the biomass and polystyrene would be linked to the overlapping release of volatiles from the biomass and polystyrene as they are released from the individual feedstocks, with volatile-volatile interaction of the pyrolysis gases and also volatile interaction from the polystyrene with char from the biomass [33, 34]. It is suggested that the interaction of the polystyrene pyrolysis gases during the co-pyrolysis is linked to interaction with the thermal degradation volatiles of the lignin and cellulose components of the biomass and with the residual solid biomass char [35].

\section{Product yield and gas composition \\ from the co-pyrolysis-catalysis of biomass:polystyrene}

Table 4 shows the product yields from the co-pyrolysis of biomass with polystyrene (1:1 ratio) coupled with catalysis in relation to different metal-ZSM-5 catalysts. Co-pyrolysis of biomass and polystyrene with the unmodified ZSM-5 catalyst resulted in a gas yield of $18.5 \mathrm{wt} \%$ and oil yield of $65.0 \mathrm{wt} . \%$ composed of $47.6 \mathrm{wt} . \%$ bio-oil and $17.4 \mathrm{wt} . \%$ water.
Modification of the ZSM-5 with metal impregnation had little effect on gas and bio-oil yield for the Cu-ZSM-5 and Fe-ZSM-5 catalysts compared to the unmodified ZSM5. However, there was increased gas and oil yield for the Co-ZSM-5 and increased gas but lowered oil yield for the Ni-ZSM-5 catalysts. The lowest gas yield of $14 \mathrm{wt} . \%$ was obtained with the Ga-ZSM-5 catalyst. The char yield remained almost the same since the pyrolysis reactor would be unaffected by the catalyst. Razzaq et al. [6] compared the product yield from the co-pyrolysis of biomass and polystyrene in the presence of different metal-ZSM-5 catalysts ( $\mathrm{Zn}, \mathrm{Co}, \mathrm{Fe}, \mathrm{Ni}$ ). They showed that the addition of metal produced a decrease in the aqueous phase and increase in the organic (oil) phase for Zn-ZSM-5, Co-ZSM-5 and Fe-ZSM-5 as also shown in this work compared to unmodified ZSM-5. They also reported that Ni-ZSM-5 produced the lowest oil yield and highest gas yield as also found in this work, although to a lesser extent. Razzaq et al. [6] did not investigate Ga-ZSM-5 catalyst, which in this work showed the lowest yield of gas compared to the unmodified ZSM-5.

Figure 3 shows the composition of the gases from the pyrolysis-catalysis of the biomass and polystyrene (1:1 ratio). The main gases are $\mathrm{CO}$ and $\mathrm{CO}_{2}$ derived from the biomass and hydrogen and hydrocarbons produced mainly from the polystyrene, but also from the biomass. The introduction of the metal-ZSM-5 catalyst increased the gas yield with higher concentrations of all gases. The increase in hydrocarbon concentration suggests further cracking of the pyrolysis hydrocarbons over the ZSM-5 catalyst, also, the deoxygenation of the oxygenated pyrolysis compounds derived from the biomass component of the mixture would produce the increase in carbon oxide gases. Addition of metals to the ZSM-5 catalyst produced most noticeably an increase in hydrogen, particularly for the Ni-ZSM-5 and Co-ZSM-5 catalysts. Iliopoulou et al. [29] investigated the flash pyrolysis of biomass in the presence of metal-impregnated ZSM-5 zeolite catalysts and also reported large increases in hydrogen yield for cobalt- and nickel-modified ZSM-5 catalysts with the hydrogen yield from nickel-ZSM-5 being more than twice that of the cobalt-ZSM-5.

The production of hydrogen is most probably due to the catalytic steam reforming of the hydrocarbons derived from
Table 4 Product yields from the catalytic co-pyrolysis of biomass with polystyrene at a mixing ratio of $1: 1$ with different ZSM-5 catalysts

\begin{tabular}{llllll}
\hline & Char (wt.\%) & Liquid (wt.\%) & Gas (wt.\%) & Water (wt.\%) & Oil (wt.\%) \\
\hline 1:1 biomass:plastic ratio & & & & \\
ZSM-5 & 16.0 & 65.0 & 18.5 & 17.4 & 47.6 \\
Ga-ZSM-5 & 14.5 & 67.0 & 14.0 & 16.7 & 50.3 \\
Co-ZSM-5 & 13.5 & 68.0 & 22.5 & 15.3 & 52.7 \\
Cu-ZSM-5 & 14.5 & 64.5 & 16.0 & 16.6 & 47.9 \\
Fe-ZSM-5 & 13.5 & 64.5 & 17.0 & 17.5 & 47.0 \\
Ni-ZSM-5 & 14.0 & 51.0 & 25.0 & 13.4 & 37.6 \\
\hline
\end{tabular}




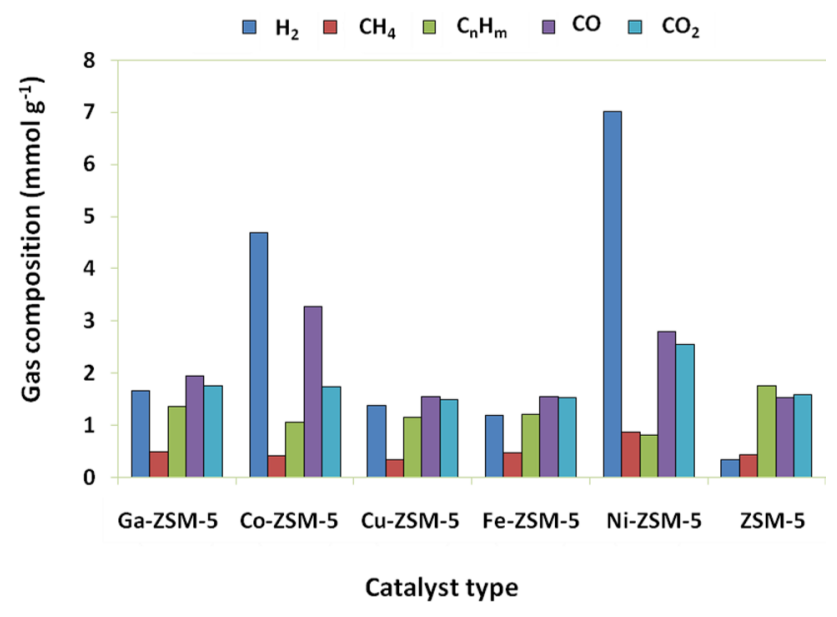

Fig. 3 The composition of the gas collected during co-pyrolysis of biomass and polystyrene with catalysis using various metal-ZSM-5 catalysts

both polystyrene and biomass $[36,37]$. The production of steam would be from the water derived from the processing of the biomass and will be due to the volatilisation of water (moisture) present in the biomass material [38]. In addition, water will also be produced as a reaction product through deoxygenation reactions of the pyrolysis gases which occur over the solid acid catalyst, ZSM-5. Nickel in particular, as well as other transition metal-based catalysts are known to promote the catalytic steam reforming of hydrocarbons for the production of hydrogen $[39,40]$. The co-pyrolysis of biomass and polystyrene with the Ni-ZSM-5 and Co-ZSM-5 catalysts produced the lowest water yield as shown in Table 4, suggesting a reduction in yield due to water being consumed in reforming reactions.

The distribution of oxygen in the products produced from the co-pyrolysis-catalytic upgrading of biomass and polystyrene was calculated in relation to the oxygen content of the feedstock. Since the polystyrene contained no oxygen, the basis for the calculation was the distribution of oxygen from the biomass into the products of $\mathrm{H}_{2} \mathrm{O}, \mathrm{CO}$ and $\mathrm{CO}_{2}$ with the oxygen content in the char and product oil calculated by difference. The results are shown in Fig. 4, and show that the oxygen is mainly removed as $\mathrm{H}_{2} \mathrm{O}$ and $\mathrm{CO}_{2}$ and at lower amounts, as CO. The Ni-ZSM-5 and Co-ZSM-5 catalysts showed the lowest water yield and highest $\mathrm{CO}_{2}$ and $\mathrm{CO}$ gas yields, as also reflected in Table 4 and Fig. 3. This suggests that the removal of oxygen from the bio-oil is via decarboxylation and decarbonylation rather than hydrodeoxygenation for the Ni-ZSM-5 and Co-ZSM-5 catalysts. Whereas the ZSM-5, Ga-ZSM-5, Cu-ZSM-5 and Fe-ZSM-5 catalysts produced higher water yield and lower $\mathrm{CO}$ and $\mathrm{CO}_{2}$ yields suggesting that oxygen removal was mainly via hydrodeoxygenation. Deoxygenation produces water by removing oxygen and hydrogen with $89 \%$ of the compound mass

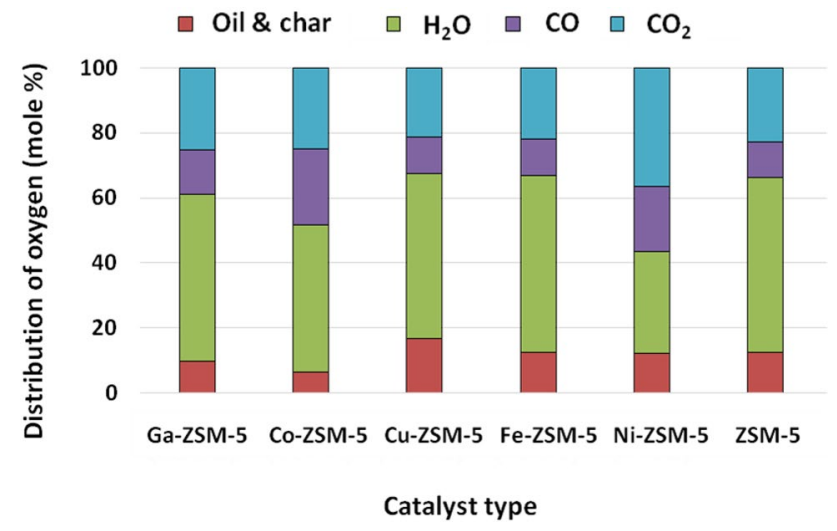

Fig. 4 Distribution of oxygen through deoxygenation reactions in the form of water, carbon monoxide, carbon dioxide with the oxygen content of char and oil from the co-pyrolysis catalysis of biomass and polystyrene

attributed to oxygen. In addition, the production of carbon oxides also reduces the oil yield by removing carbon with the oxygen, with $57 \%$ of carbon monoxide mass due to oxygen and $73 \%$ of carbon dioxide due to oxygen. During deoxygenation of biomass, it is advantageous to remove oxygen through carbon dioxide to minimise mass loss and limit reductions to the $\mathrm{H}: \mathrm{C}$ ratio which is important for formation of oil compounds rather than coke. However, when polystyrene is present, the $\mathrm{H}: \mathrm{C}$ ratio is increased significantly thereby hydrodeoxygenation is promoted as there is hydrogen available and this reduces the mass of oil, to a smaller degree, per oxygen atom removed.

\section{Oil composition from the co-pyrolysis-catalysis of biomass:polystyrene}

The product oil fraction separated from the liquid product produced from the co-pyrolysis-catalysis of the biomass:polystyrene mixture with the different metal-ZSM-5 catalysts was analysed by GC-MS. The GC-MS total ion chromatogram was very complex showing a wide variety of chemical classes. The GC-MS analysis was used to categorise the different aromatic ring containing compounds and the results are shown in Fig. 5 for the different metal-ZSM-5 catalysts. The dominant class of compounds were single-ring aromatic compounds and to a lesser extent polycyclic aromatic hydrocarbons (PAH). Some oxygenated aromatic compounds, mainly phenolic compounds were also present. The influence of the metal impregnated onto the ZSM-5 showed that the unmodified ZSM-5 and the Ga-ZSM-5 catalysts produced the lowest yield of singlering aromatic compounds, but produced the highest yield of PAH. However, the Co-ZSM-5, Cu-ZSM-5, Fe-ZSM-5 and Ni-ZSM-5 all improved the yield of single-ring aromatic compounds compared to the unmodified ZSM-5. 
Fig. 5 Types of compounds which comprise the aromatic component in the product oil from the co-pyrolysis catalysis of biomass and polystyrene

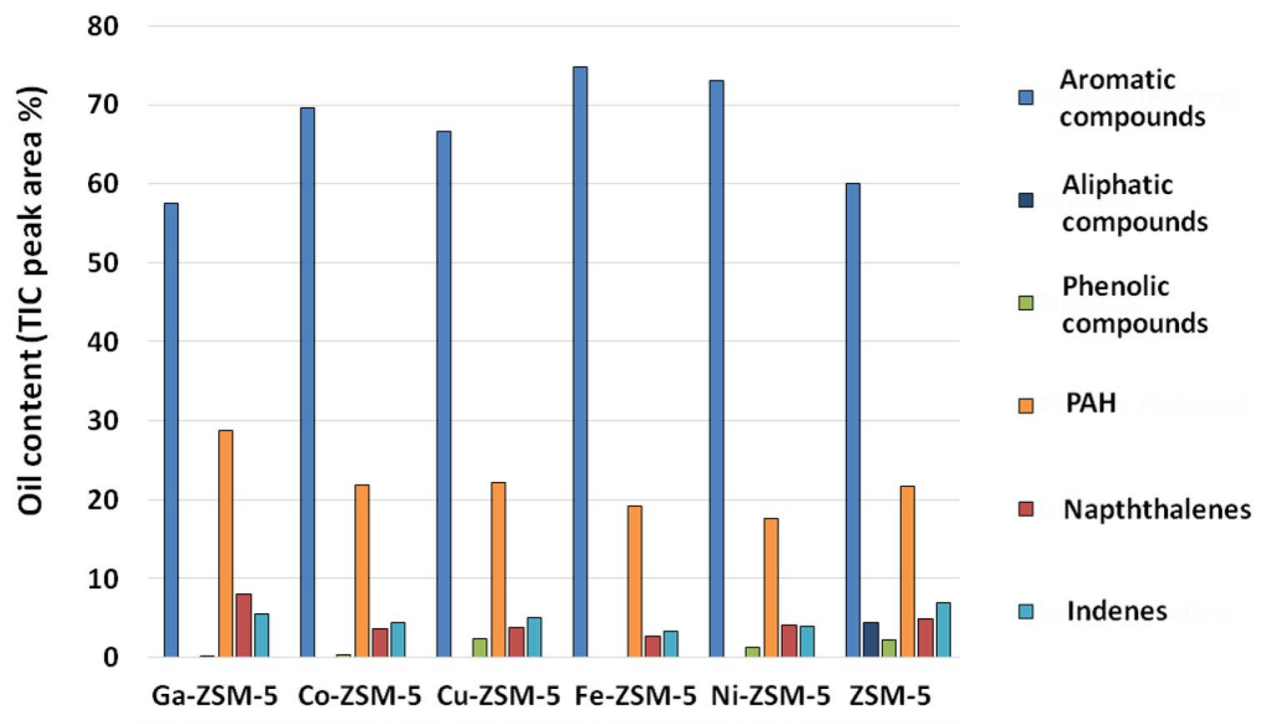

Catalyst type
Other researchers have reported the influence of metal addition to zeolite ZSM-5 for the improvement of bio-oil quality in relation to biomass pyrolysis. Veses et al. [41] studied the upgrading of bio-oil using $1 \mathrm{wt} . \%$ metal-impregnated ZSM-5 catalysts ( $\mathrm{Ga}, \mathrm{Cu}, \mathrm{Ni}, \mathrm{Mg}$ and $\mathrm{Sn}$ ) and found that the aromatic fraction (phenols, primary aromatics and polycyclic aromatic hydrocarbons) determined by semiquantitative GC-MS analysis increased from $~ 59 \%$ in the raw bio-oil to between 74 and $79 \%$ in the metal-impregnated catalysts. Che et al. [42] found that the addition of a range of metals $(\mathrm{Zn}, \mathrm{Fe}, \mathrm{Ca}$, Le and $\mathrm{La}$ ) to $\mathrm{ZSM}-5$ produced a reduction in two-ring naphthalene and methylnaphthalene for all the metal-ZSM-5 catalysts. Zhang et al. [43] investigated various loadings ( $0-8$ wt. \%) of Fe-modified ZSM-5 for the catalytic pyrolysis of risk husks. The increase in iron loading increased benzene and toluene yield whilst also increasing the yield of naphthalenes and naphthalene derivatives.

Figure 6 shows the individual single-ring aromatic compounds in the product oil with the different types of metal catalyst. Clearly, the dominant single-ring aromatic compound is styrene, derived from the polystyrene. Pyrolysis of polystyrene alone can produce high yields of oil, of over $95 \%$, with a composition of mostly styrene with lower concentrations of styrene oligomers and other aromatic compounds, mainly toluene and ethylbenzene [10, 44, 45]. Consequently, it would be expected that the co-pyrolysis of biomass and polystyrene would produce a product biooil with a significantly higher concentration of aromatic
Fig. 6 Single-ring aromatic compounds in the product oil from the co-pyrolysis catalysis of biomass and polystyrene

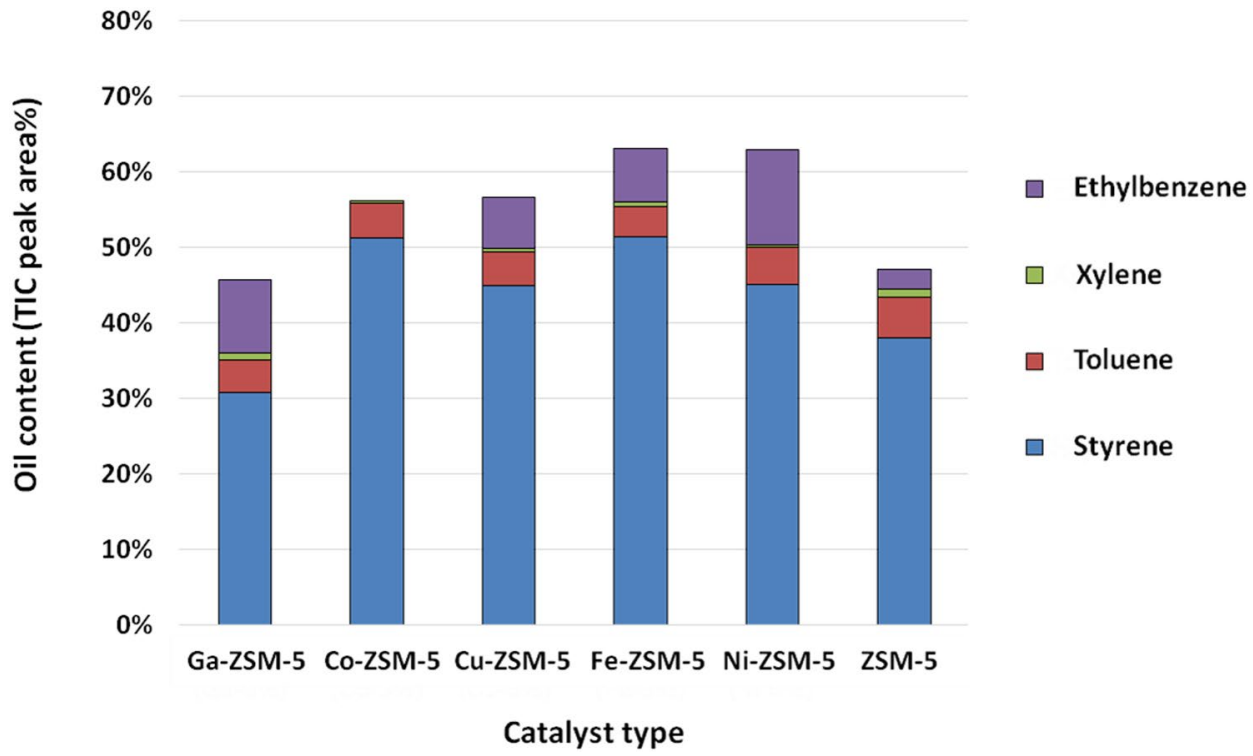


compounds. Indeed, Reshad et al. [19], co-pyrolysed biomass and polystyrene in a semi-batch reactor and reported high concentrations of styrene, methyl styrene, xylene and also high concentrations of aliphatic compounds in the product bio-oil. Kumar and Srinivas [27] also reported a product oil containing abundant styrene, methylstyrene, toluene and ethylbenzene for the co-pyrolysis of biomass and polystyrene in a semi-batch reactor. Muneer et al., [26] reported a synergistic increased oil yield for the co-pyrolysis of biomass and polystyrene in a fixed bed reactor above that expected by calculation of the individual feedstock pyrolysis which was attributed to donation of hydrogen and the cross-reaction between the biomass and the polystyrene.

Compared with the unmodified ZSM-5, the impregnation of metals onto the ZSM-5 resulted in an increase in the concentration of the single-ring compounds, except for Ga-ZSM-5. However, it should be noted that the GC-MS total ion chromatogram peak areas shown in Fig. 6 on oil composition should also be related to the total oil yield data for each metal-ZSM-5 catalysts shown in Table 4. Apart from Co-ZSM-5, all the metal-impregnated catalysts showed an increase in ethylbenzene formation. The pyrolysis-catalysis of polystyrene with ZSM- 5 has previously been shown to produce benzene rather than ethylbenzene [45], suggesting the presence of the biomass in co-pyrolysis-catalysis promotes ethylbenzene formation.

Zeolite catalysts are acid catalysts which promote dehydration, decarboxylation, decarbonylation, hydrodeoxygenation, cracking and aromatisation reactions [7, 46, 47]. Zeolites are porous crystalline lattice structures, generally composed of silicon, aluminium and oxygen, in a tetrahedral structure. The acidity of zeolite catalysts and hence their catalytic activity is related to the ratio of silicon and aluminium with a higher relative surface alumina concentration and thereby lower $\mathrm{Si}$ :Al ratios producing higher surface acidity and thereby increased catalyst activity [48, 49]. In particular, the strong acid sites of the zeolite ZSM-5 with its associated microporous structure mainly promote aromatisation reactions to produce high yields of single-ring aromatic hydrocarbons [7, 23]. Zeolites are not only catalytically active but also very selective. The selectivity is due in large part to the ability of zeolites to constrain reactions by restricting products to those which can be produced and diffuse through the geometric limitations of the pore structure $[48,50]$. For example, zeolite ZSM-5, contains medium sized pores allowing for hydrocarbon rings of up to 10 carbon atoms to diffuse into the structure for reaction, whereas larger molecules are constrained. In addition, it is also possible for reactions to take place on the surface of the zeolite catalyst (external active sites). These external reactions are not constrained in the same way as compounds which react within the pores, however, many of the reactive sites will only be available in the internal framework of the zeolite
$[48,51]$. Table 2 shows that the addition of the metals to the ZSM-5 resulted in a decrease in surface area and also pore volume, particularly for the addition of $\mathrm{Cu}, \mathrm{Co}$ and $\mathrm{Ga}$ to the ZSM-5; suggesting some constraint of the hydrocarbon reactants accessibility to the catalyst active sites for reaction. For example, the lowest production of aromatic compounds was with Ga-ZSM-5, Co-ZSM-5 and Cu-ZSM-5 catalysts, which also showed the largest reduction in surface area and pore volume compared to the unmodified ZSM-5 catalyst; suggesting that steric effects of surface area and porosity may also influence the access to active metal catalytic sites [30].

Liu et al. [48] have reviewed the catalyst parameters that influence the composition of bio-oil from the fast pyrolysis-catalysis of biomass, including the influence of metal additives to zeolite. They reported that metal-impregnated zeolites, such as Fe-ZSM-5, Ni/Co-ZSM-5 and Ga-ZSM-5, increase the selectivity towards the formation of aromatic hydrocarbons. They suggested that the presence of metal enhances the hydrocarbon yield by ensuring available hydrogen for the formation of hydrocarbon molecules. Zheng et al. [30] reported the effect of $1 \%$ loading of $\mathrm{Zn}, \mathrm{Mg}, \mathrm{Ga}, \mathrm{Ni}$, $\mathrm{Co}$, and $\mathrm{Cu}$ on ZSM-5, for catalytic pyrolysis of pine wood. When Ga-ZSM-5 catalyst was used, an increase for both single-ring and two-ring aromatic compounds was found. In terms of individual aromatic compounds, they reported different selectivities between the investigated metal-ZSM-5 catalyst for toluene, benzene and xylene.

For the co-pyrolysis of biomass and plastics coupled with ZSM-5 catalysis, it has been reported that the addition of metals to the zeolite ZSM-5 improves the quality of the upgraded bio-oil, by enhancing hydrogen transfer from the plastic volatiles to the biomass volatiles resulting in improved aromatisation reactions. For example, it has been reported that Fe-ZSM-5 produced higher levels of deoxygenation and higher aromatisation efficiency associated with enhanced hydrogen transfer compared with unmodified ZSM-5 catalyst [6]. In addition, Lee et al. [52] reported that co-pyrolysis-catalysis with Co-ZSM-5, Ni-ZSM-5, Zn-ZSM-5 and Fe-ZSM-5 catalysts produced lower catalyst coke formation compared with unmodified ZSM-5. Ni-ZSM-5 catalyst was also reported to increase the formation of aromatic hydrocarbons and alky phenols with reduced formation of alkoxy phenols due to induced increased hydrogen transfer from the plastic due to the nickel metal [52]. Figures 5 and 6 also show enhanced yields of single-ring aromatic hydrocarbons with Ni-ZSM-5 and Fe-ZSM-5 catalysts compared to the other metal-modified and unmodified ZSM- 5 catalysts.

The addition of metal to ZSM-5 catalysts has been shown to assist aromatic formation via favouring of dehydrogenation reactions as well as by reducing the number of Brønsted acid sites and at the same time causing more Lewis acid 
sites to form [53, 54]. Catalytic cracking occurs on the catalyst acidic surface on Lewis or Brønsted acid sites, where the polymer fragments arising from pyrolysis are cracked to form a range of carbon cations [46, 49]. These acidic sites form where there are defects in the crystalline structure and by necessity are at the surface of the material to enable interaction with the reactants. A Brønsted acid site is a strong acid site which forms where a silicon-oxygen-silicon bridge is altered through the exchange of one silicon atom for an aluminium atom. This produces an uneven charge on the bridging oxygen which will then gain stabilisation as a hydroxide group. The hydroxide bridge may lose this proton relatively easily with stabilisation of the negative charge on the oxygen $[49,55]$. Lewis acid sites can be formed by delamination of the zeolite framework on external surfaces. These acid sites are much weaker than Brønsted acid sites. However, a Lewis acid site positioned near a Brønsted acid site may help withdraw electrons from the bridging $\mathrm{OH}$ which in the Brønsted acid site and lead to a superacidic Brønsted acid site [56].

Catalyst surface effects will also be crucial in the formation of aromatic compounds, with internal surfaces templating aromatic compounds whilst external surfaces may produce polycyclic aromatic compounds. The ratio of internal to external surfaces will also depend on metalcatalyst loading amongst other factors [51]. Cheng et al. [57] investigated Ga-ZSM-5 catalysts for the production of aromatic compounds from lignocellulosic biomass and suggested that whilst the metal atoms could replace protons within the material and encouraged decarbonylation of furan molecules leading to aromatisation of alkenes (olefins) this was hindered if Brønsted acid sites were unavailable. It was proposed that the metal functions in conjunction with the catalyst acid sites to promote aromatic formation. In addition, research by Zheng et al. [30] suggested that the relationship between catalyst acid sites and metal atoms was complex, with the possibility of synergy between Lewis acid sites, Brønsted acid sites and metal atoms as well as competition between them. This is further complicated by the introduction of the metal atoms leading to both increases and decreases in the strength of these acid sites within a material. Steric effects for the ZSM-5 catalysts enhances selectivity, these solid acid catalysts, constraining reactions by the geometric limitations of the pores [50]. The mesoporosity of ZSM-5 resulting in reaction selectively producing single-ring aromatic compounds such as p-xylene, benzene and toluene with larger compounds becoming too large to pass through the internal pores of the zeolite. Steric effects may also be introduced during metal impregnation with a potential reduction in internal surface, external surfaces or pore blocking.

Razzaq et al. [6] used a two-stage fixed bed pyrolysis-catalysis reactor using biomass (wheat straw) and polystyrene co-pyrolysis with ZSM-5 and metal-modified ZSM-5 (Co-ZSM-5, Ni-ZSM-5, Zn-ZSM-5 and Fe-ZSM$5)$ catalysts in a downstream reactor. They reported an increase in styrene content in the presence of all the metal-ZSM-5 catalysts compared with the unmodified catalyst. This was attributed to the reduction in catalyst acidity by addition of the metals resulting in reduced catalytic cracking of the pyrolysis gases. The results reported here also showed an increase in styrene formation in the presence of the metal-ZSM-5 catalysts (the exception being Ga-ZSM-5). The increase in styrene formation was at a much greater extent compared to the results of Razzaq et al. [6]. However, the feedstock ratio to catalyst in their work was $1: 0.5$, whereas in this work there ratio was $1: 2$, resulting in higher catalytic cracking. The Ga-ZSM-5 catalyst showed the lowest yield of aromatic compounds from the co-pyrolysis of biomass and polystyrene (Figs. 5, 6). However, Cheng et al. [58] reported that Ga-ZSM-5 was effective in producing aromatic compounds from the catalytic fast pyrolysis of biomass. It was suggested that gallium increases the rate of decarbonylation and alkene aromatisation and the ZSM-5 acts to catalyse other reactions such as oligomerisation. They also suggested that the presence of Ga decreases the catalyst acidity, resulting in low coke formation and enhanced catalytic activity. Therefore, the results reported here suggest that the Ga-ZSM-5 is less effective in promoting aromatisation reactions for the polystyrene pyrolysis vapours compared to the other metal-catalysts investigated during copyrolysis. For example, Iftikhar et al. [25] suggested that the formation of compounds from the decomposition of biomass was suppressed by polystyrene decomposition intermediates during the co-pyrolysis of biomass (sugarcane bagasse) and polystyrene with metal-ZSM-5 catalysis.

\section{Influence of higher biomass:polystyrene ratio (4:1) on product yield and gas composition}

The co-pyrolysis-catalysis of biomass:polystyrene was studied in the previous sections at a biomass:polystyrene ratio of $1: 1$. To extend the work, the influence of a lower content of polystyrene in the mixture of biomass:polystyrene used for co-pyrolysis-catalysis was investigated. A biomass:polystyrene ratio of 4:1 was used and the product oil and gas yield and composition was determined in relation to different metal-ZSM-5 catalysts. Only a selection of metal-ZSM-5 catalysts were used, the Cu-ZSM-5, Ga-ZSM-5 and Co-ZSM-5 catalysts were used in the comparison with unmodified ZSM-5.

Table 5 shows the product yield from the co-pyrolysis-catalysis for the 4:1 ratio of biomass:polystyrene. Comparison with the product yield data in Table 4 for the 1:1 ratio of biomass:polystyrene shows a proportional increase in the yield of char for all the catalysts, commensurate with 
Table 5 Product yields from the catalytic co-pyrolysis of biomass with polystyrene at a mixing ratio of $4: 1$ with different ZSM-5 catalysts

\begin{tabular}{llllll}
\hline & Char (wt.\%) & Liquid (wt.\%) & Gas (wt.\%) & Water (wt.\%) & Oil (wt.\%) \\
\hline 4:1 biomass:plastic ratio & & & & \\
ZSM-5 & 22.0 & 59.5 & 22.3 & 34.1 & 25.4 \\
Ga-ZSM-Ga & 21.5 & 51.0 & 28.5 & 29.7 & 21.3 \\
Co-ZSM-5 & 22.0 & 41.5 & 34.0 & 27.3 & 14.2 \\
Cu-ZSM-5 & 22.5 & 48.5 & 27.5 & 27.9 & 20.6 \\
\hline
\end{tabular}

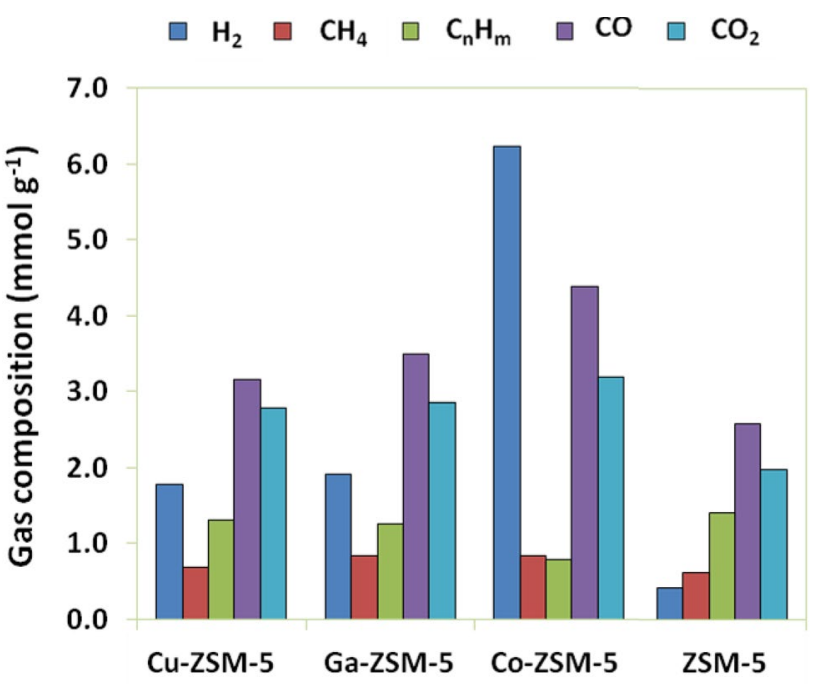

Catalyst type

Fig. 7 The composition of the gas collected during co-pyrolysis of biomass and polystyrene at a ratio of $4: 1$ with catalysis using various metal-ZSM- 5 catalysts

the increased amount of biomass. Figure 2 shows that biomass provides the char during co-pyrolysis with polystyrene producing no char. Table 5 also shows that increased amounts of biomass in the feedstock leads to lower liquid yield, including lower oil yield and higher gas yield compared to the co-pyrolysis of the biomass:polystyrene at the ratio of 1:1 (Table 4). Figure 7 shows the gas composition for the co-pyrolysis catalysis with the Cu-ZSM-5, Ga-ZSM-5 and Co-ZSM- 5 catalysts. Addition of cobalt to the ZSM-5 produced the highest yield of hydrogen and also $\mathrm{CO}$ and $\mathrm{CO}_{2}$, suggesting higher levels of deoxygenation by carbonylation. The use of Co-ZSM-5 with co-pyrolysis of biomass and polystyrene at a ratio of $1: 1$ also produced enhanced $\mathrm{H}_{2}$, $\mathrm{CO}$ and $\mathrm{CO}_{2}$ yield.

Figure 8 shows the distribution of oxygen through deoxygenation reactions in the form of water, carbon monoxide, carbon dioxide and the oxygen content of char and oil for the co-pyrolysis of biomass:polystyrene (ratio 4:1). The high deoxygenation indicated by the decarbonylation and decarboxylation of oxygenated compounds to produce $\mathrm{CO}$ and $\mathrm{CO}_{2}$ and hydrodeoxygenation to produce $\mathrm{H}_{2} \mathrm{O}$. For the

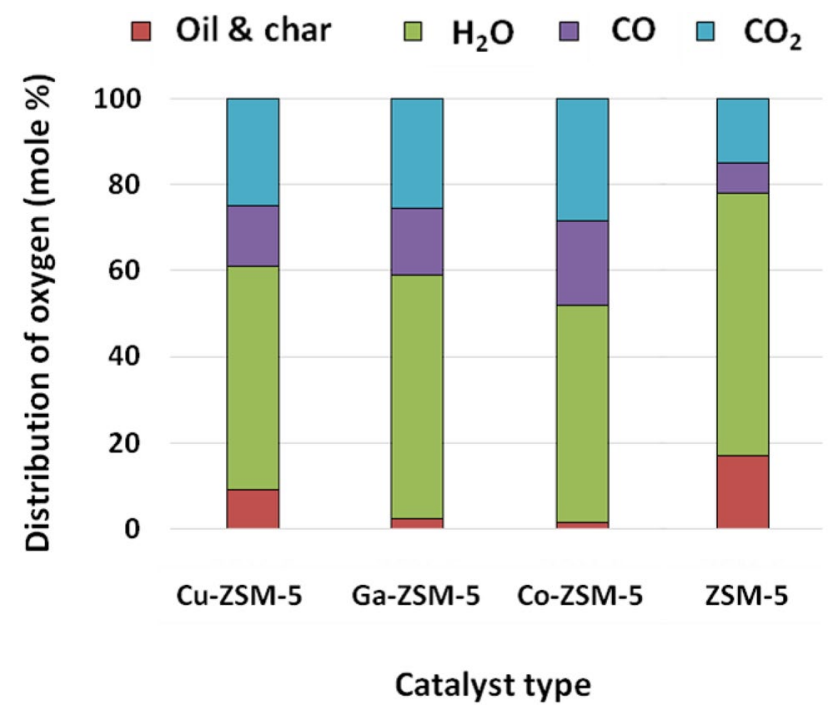

Fig. 8 Distribution of oxygen through deoxygenation reactions in the form of water, carbon monoxide, carbon dioxide with the oxygen content of char and oil from the co-pyrolysis catalysis of biomass and polystyrene at a ratio of $4: 1$

unmodified ZSM-5, the oxygen was removed mainly as $\mathrm{H}_{2} \mathrm{O}$ via hydrodeoxygenation with lower levels of $\mathrm{CO}$ and $\mathrm{CO}_{2}$ compared with the metal-ZSM-5 catalysed process. As also, shown in Fig. 8, the Co-ZSM-5 catalyst produced the highest $\mathrm{CO}$ and $\mathrm{CO}_{2}$, indicating higher decarbonylation and decarboxylation.

\section{Influence of higher biomass:polystyrene ratio (4:1) on product oil composition}

The upgraded bio-oil from the co-pyrolysis of biomass:polystyrene at a ratio of $4: 1$ with the Cu-ZSM-5, Ga-ZSM-5 and Co-ZSM-5 catalysts was analysed for the various aromatic ring containing compounds and the results are shown in Fig. 9. Increasing the biomass:polystyrene ratio to $4: 1$ for the unmodified ZSM-5 catalyst produced a reduced amount of single-ring aromatic compounds and PAH compared to the 1:1 ratio. In relation to $\mathrm{Cu}-\mathrm{ZSM}-5$ and Co-ZSM-5 catalysts, the yield of single-ring aromatic compounds produced from the 4:1 ratio of biomass:polystyrene was decreased in comparison with the 1:1 ratio mixture (Fig. 5). However, for the Ga-ZSM-5 catalyst, the content 


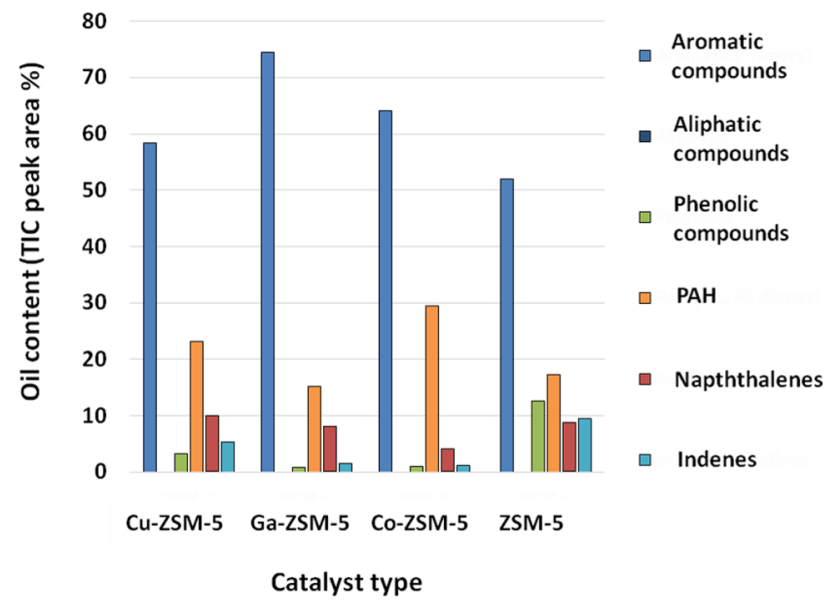

Fig. 9 Types of compounds which comprise the aromatic component in the product oil from the co-pyrolysis catalysis of biomass and polystyrene at a ratio of $4: 1$

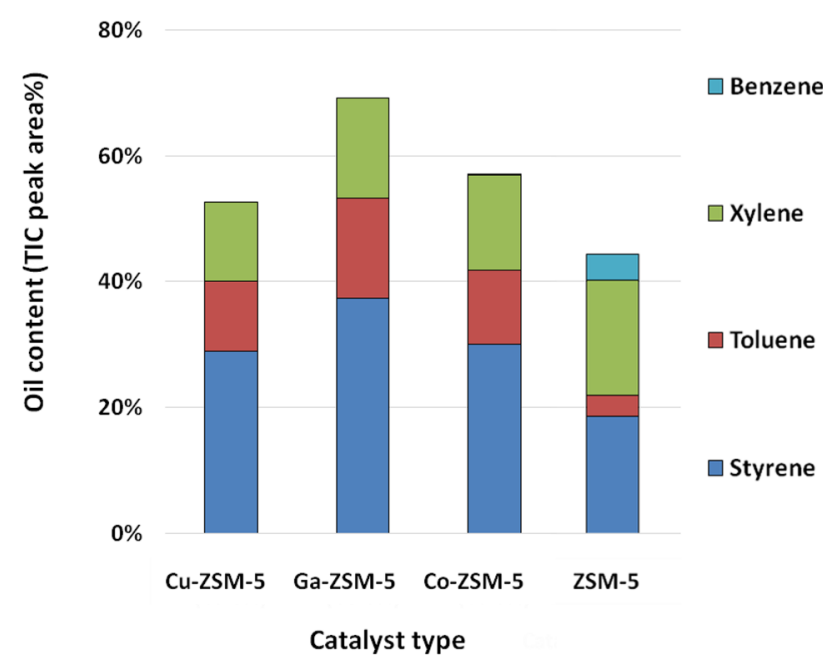

Fig. 10 Single-ring aromatic compounds in the product oil from the co-pyrolysis catalysis of biomass and polystyrene at a ratio of $4: 1$

of single-ring aromatic compounds in the product oil showed an increase with a reduction in PAH compared to the $1: 1$ ratio mixture.

The relative proportions of the single-ring aromatic compounds identified in the product bio-oil (total ion chromatogram peak area) from the 4:1 co-pyrolysis of biomass:polystyrene are shown in Fig. 10. The results show that compared to the $1: 1$ ratio of biomass:polystyrene, the yield of styrene and toluene was reduced. In addition, the content of xylenes was increased and benzene rather than ethylbenzene was produced. When metal-ZSM-5 catalysts were used with the 4:1 biomass:polystyrene copyrolysis ratio, the yield of styrene for the Co-ZSM-5 and $\mathrm{Cu}-\mathrm{ZSM}-5$ catalysts was reduced, but for the Ga-ZSM-5, it was increased in the bio-oil. It should be noted that Table 5 shows that the yield of bio-oil was markedly reduced for the $4: 1$ ratio of biomass:polystyrene compared with the $1: 1$ ratio oil yields shown in Table 4 . The oil yields using the Ga-ZSM-5, Co-ZSM-5, and Cu-ZSM-5 catalysts were $21.3 \mathrm{wt} . \%, 14.2 \mathrm{wt} . \%$ and $20.6 \mathrm{wt} . \%$ for the $4: 1$ ratio but significantly higher at $50.3 \mathrm{wt} . \%, 52.7 \mathrm{wt} . \%$ and $47.9 \mathrm{wt} . \%$, respectively, for the 1:1 ratio biomass:polystyrene.

\section{Upgraded biomass:polystyrene derived bio-oils as potential liquid fuels and chemical feedstocks}

The catalytically upgraded bio-oils from the co-pyrolysis of biomass and polystyrene with ZSM-5 catalysts were also analysed for their liquid fuel properties by simulated distillation (ASTM method D3710) using the total ion gas chromatograms to determine their boiling range distribution. The results are shown in Fig. 11 for selected bio-oils for clarity and compared with the simulated distillation of EO grade gasoline obtained from the processing of petroleum. The crude biomass pyrolysis oil contained a high proportion $(\sim 75 \%)$ of compounds with a boiling range distribution above $200{ }^{\circ} \mathrm{C}$ representing a high content of high molecular weight, oxygenated compounds. Only approximately $25 \%$ of the crude bio-oil compounds evaporated below $200{ }^{\circ} \mathrm{C}$, compared to EO range gasoline with $95 \%$ of compounds with a boiling range below $200{ }^{\circ} \mathrm{C}$. The influence of adding unmodified zeolite ZSM-5 catalyst to the co-pyrolysis of biomass and polystyrene produced a marked change in the distillation range of the upgraded bio-oil. The proportion of compounds in the product bio-oil with a boiling range distribution below $200{ }^{\circ} \mathrm{C}$ increased to $65 \%$. Decreasing the amount of polystyrene in the co-pyrolysis mixture $(4: 1$ biomass:polystyrene ratio) with the unmodified ZSM-5 catalyst produced an oil with a lower boiling range. The introduction of metal $(\mathrm{Ga})$ to the ZSM-5 caused a decrease in the proportion of boiling range compounds below $200{ }^{\circ} \mathrm{C}$ to $60 \%$ (Bms:Ps Ga-ZSM-5). But at the higher 4:1 biomass polystyrene ratio, the upgraded oil showed the closest boiling range distribution to gasoline, with $\sim 75 \%$ of compounds boiling below $200{ }^{\circ} \mathrm{C}$. The upgraded bio-oil from the co-pyrolysis of biomass:polystyrene with the Ga-ZSM-5 (1:1) catalyst also showed the lowest content of single-ring aromatic compounds (Figs. 5 and 6) and the 4:1 ratio for Ga-ZSM-5 showed the highest content of single-ring compounds (Figs. 9 and 10). However, again it should be noted that the oil yield using Ga-ZSM-5 for the 4:1 biomass polystyrene ratio was only $21.3 \mathrm{wt}$.\% compared with the $1: 1$ ratio where the oil yield was $50.3 \mathrm{wt} . \%$.

The co-pyrolysis-catalysis of the biomass:polystyrene mixture produces a high yield of oil which contains high concentrations of styrene, and also toluene, and ethylbenzene which are regarded as valuable chemical feedstocks in high demand [59]. Styrene is mainly used for the production 
Fig. 11 Distillation range of bio-oils compared to EO grade gasoline

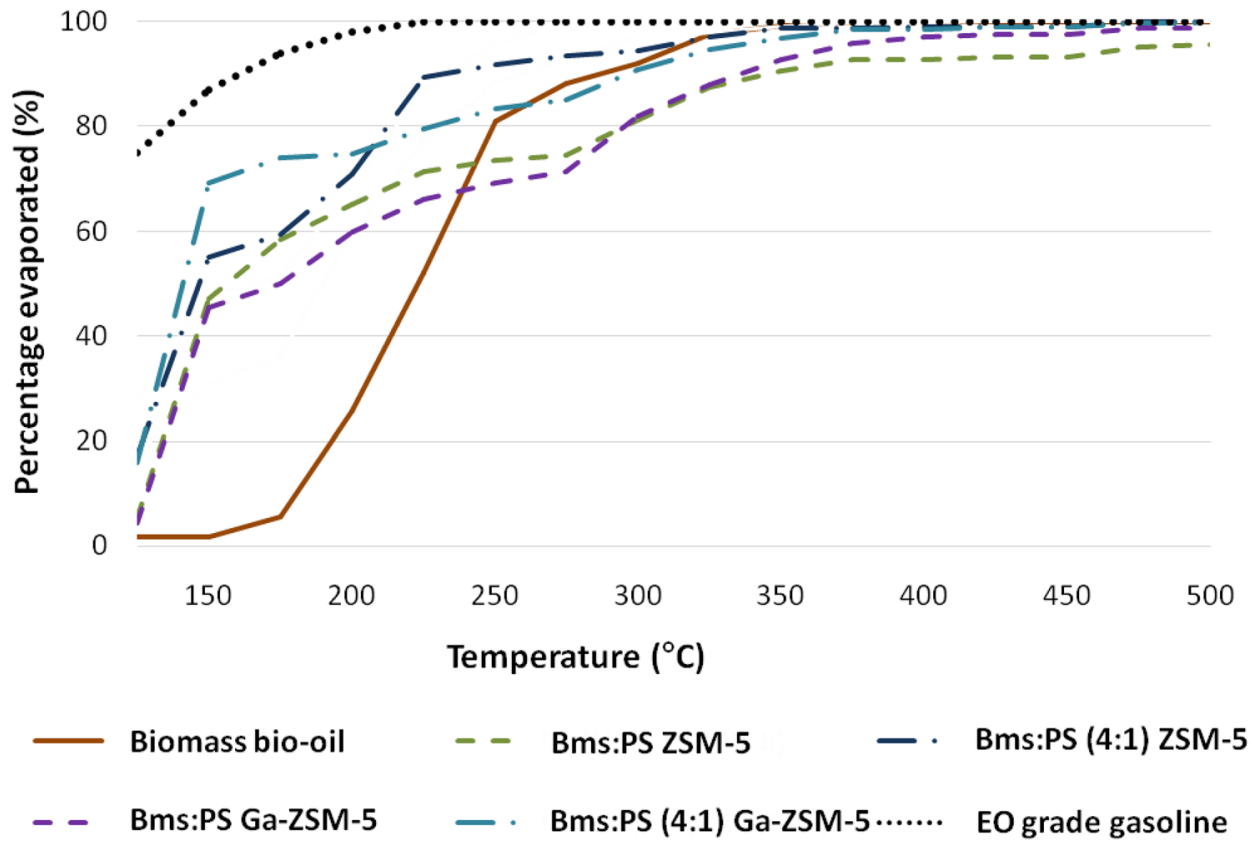

of plastics such as polystyrene plastic, expanded polystyrene, styrene acrylonitrile, high impact polystyrene, acrylonitrile butadiene styrene and also for the production of synthetic rubbers such as styrene-butadiene rubber. The annual global consumption of styrene (2017) was estimated at 29.4 million tonnes [60]. Co-pyrolysis of biomass and polystyrene also produces ethylbenzene, where the main chemical feedstock application is for the production of styrene and thereby ultimately polystyrene plastics and rubbers. Toluene, may also be used to produce benzene followed by styrene production, also toluene itself is mostly used as a component of gasoline.

\section{Conclusions}

A two-stage co-pyrolysis-catalyst reactor system with a biomass:polystyrene feedstock mixture was used to produce an upgraded bio-oil in the presence of different metal-impregnated ZSM-5 catalysts ( $\mathrm{Ga}, \mathrm{Co}, \mathrm{Cu}, \mathrm{Fe}, \mathrm{Ni}$ ). The product oils and gases were analysed in detail. The results showed that, compared with unmodified ZSM-5 catalyst, the introduction of metal to the ZSM-5 variously influenced the yield of oil, with little effect for the Cu-ZSM-5 and Fe-ZSM-5 catalysts, increased oil yield for the Co-ZSM-5 and Ga-ZSM-5 and lowered oil yield for the Ni-ZSM-5 catalysts. The main gases produced were $\mathrm{CO}$ and $\mathrm{CO}_{2}$ produced from biomass decomposition whereas hydrogen and hydrocarbons were derived mainly from the decomposition of polystyrene, but also from biomass. Deoxygenation of the bio-oils was produced with the metal-modified ZSM-5 catalysts, with Ga-ZSM-5, $\mathrm{Cu}-\mathrm{ZSM}-5$ and Fe-ZSM-5 mainly via hydrodeoxygenation and the Ni-ZSM-5 and Co-ZSM-5 catalysts mainly via decarboxylation and decarbonylation.

The yield of single-ring aromatic compounds in the product oil was increased for the Co-ZSM-5, Cu-ZSM5, Fe-ZSM-5 and Ni-ZSM-5 catalyst compared to the unmodified ZSM-5, and these catalysts also produced increased styrene content. However, the single-ring aromatic compounds in the product oil with the Ga-ZSM-5 catalyst showed reduced content of single-ring aromatic compounds and also reduced styrene content, but the highest yield of PAH. Increasing the amount of biomass compared to polystyrene (4:1 ratio) produced a significantly lower oil yield and higher gas yield compared to the co-pyrolysis catalysis of the biomass:polystyrene at the ratio of $1: 1$.

Acknowledgements We gratefully acknowledge the support of the UK Engineering \& Physical Science Research Council for a research scholarship for one of us (ACD)

Funding The research was partially funded via a $\mathrm{PhD}$ Research Scholarship from the UK Engineering \& Physical Science Research Council.

Data availability Data are available from the authors on request.

Code availability Not applicable.

\section{Declarations}

Conflict of interest The authors declare no conflict of interest or competing interests. 
Open Access This article is licensed under a Creative Commons Attribution 4.0 International License, which permits use, sharing, adaptation, distribution and reproduction in any medium or format, as long as you give appropriate credit to the original author(s) and the source, provide a link to the Creative Commons licence, and indicate if changes were made. The images or other third party material in this article are included in the article's Creative Commons licence, unless indicated otherwise in a credit line to the material. If material is not included in the article's Creative Commons licence and your intended use is not permitted by statutory regulation or exceeds the permitted use, you will need to obtain permission directly from the copyright holder. To view a copy of this licence, visit http://creativecommons.org/licenses/by/4.0/.

\section{References}

1. Dahmen N, Lewandowski I, Zibek S, Weidtmann A (2019) Integrated lignocellulosic value chains in a growing bioeconomy: status quo and perspectives. Global Change Biol Bioenergy 11:107-117

2. Sharifzadeh M, Sadeqzadeh M, Guo M, Borhani TN, Konda NVM, Garcia C, Wang L, Hallett J, Shah N (2019) The multiscale challenges of biomass fast pyrolysis and bio-oil upgrading: review of the state of the art and future research directions. Prog Energy Combust Sci 71:1-80

3. Zacher AH, Olarte MV, Santosa DM, Elliot DC, Jones SB (2014) A review and perspective of recent bio-oil hydrotreating research. Green Chem 16:491-515

4. Kabir G, Hameed BH (2017) Recent progress on catalytic pyrolysis of lignocellulosic biomass to high-grade bio-oil and bio-chemicals. Renew Sustain Energy Rev 20:945-967

5. Kim E, Gil H, Park S, Park J (2017) Bio-oil production from pyrolysis of waste sawdust with catalyst ZSM-5. J Mater Cycles Waste Manag 19:423-431

6. Razzaq M, Zeeshan M, Qaisar S, Iftikar H, Muneer B (2019) Investigating use of metal-modified HZSM-5 catalyst to upgrafe liquid yield an co-pyrolysis of wheat straw and polystyrene. Fuel. https://doi.org/10.1016/j.fuel.2019.116119

7. Ryu HW, Kim DH, Jae J, Lam SS, Park ED, Park YK (2020) Recent advances in catalytic co-pyrolysis of biomass and plastic waste for the production of petroleum-like hydrocarbons. Bioresour Technol. https://doi.org/10.1016/j.biortech.2020.123473

8. Vasile C, Brebu M, Darie H, Cazacu G (2010) Effect of some environmentally degradable materials on the pyrolysis of plastics II: influence of cellulose and lignin on the pyrolysis of complex mixtures. J Mater Cycles Waste Manag 12:147-153

9. Bhagat SP, Gera P, Bhavanam A (2018) Catalytic co-pyrolysis of Pterospermum acerifolium and plastic waste. J Mater Cycles Waste Manag 20:1923-1933

10. Lee A, Liew MS (2021) Tertiary recycling of plastic waste: an analysis of feedstock, chemical and biological degradation methods. J Mater Cycles Waste Manag 23:32-43

11. Geyer R, Jambeck JR, Law KL (2017) Production, use and fate of all plastics ever made. Sci Adv. https://doi.org/10.1126/sciadv. 1700782

12. PlasticsEurope - Plastics the Facts, 2019, Plastics Europe, Brussels, 2020.

13. Sharuddin SDA, Abnisa F, Daud WMAW, Aroua MK (2016) A review on pyrolysis of plastic waste. Energy Convers Manag 115:308-326

14. Lopez G, Artetxe M, Amutio M, Bilbao J, Olazar M (2017) Thermochemical routes for the valorization of waste polyolefinic plastics to produce fuels and chemicals. A review. Renew Sustain Energy Rev 73:346-368
15. Abnisa F, Wan Daud WMA (2014) A review on co-pyrolysis of biomass: an optional technique to obtain a high-grade pyrolysis oil. Energy Convers Manag 87:71-85

16. Hassan H, Lim JK, Hameed BH (2016) Recent progress on biomass co-pyrolysis conversion into high-quality bio-oil. Biores Technol 221:645-655

17. Uzoejinwa BB, He X, Wang S, Abomohra AE, Hu Y, Wang Q (2018) Co-pyrolysis of biomass and waste plastics as a thermochemical conversion technology for high-grade biofuel production: recent progress and future directions elsewhere worldwide. Energy Convers Manag 163:468-492

18. Ozsin G, Putun AE (2017) Insights into pyrolysis and co-pyrolysis of biomass and polystyrene: thermochemical behaviours, kinetics and evolved gas analysis. Energy Convers Manag 149:675-685

19. Reshad AS, Tiwari P, Goud VV (2019) Thermal and co-pyrolysis of rubber seed cake with waste polystyrene for bio-oil production. J Anal Appl Pyrolysis 139:333-343

20. Nguyen QV, Choi YS, Choi SK, Jeong YW, Kwon YS (2019) Improvement of bio-crude oil properties via co-pyrolysis of pine sawdust and waste polystyrene foam. J Environ Manag 237:24-29

21. Sanahuja-Parejo O, Veses A, Navarro MV, Lopez JM, Murillo R, Callen MS, Garcia T (2019) drop-in biofuels from the co-pyrolysis of grape seeds and polystyrene. Chem Eng J. https://doi.org/ 10.1016/j.cej.2018.10.183

22. Mortensen PM, Grunwaldt JD, Jensen PA, Knudsen KG, Jensen AD (2011) A review of catalytic upgrading of bio-oil to engine fuels. Appl Catal A Gen 407:1-19

23. Zhang X, Lei H, Chen S, Wu J (2016) Catalytic co-pyrolysis of lignocellulosic biomass with polymers: a critical review. Green Chem 18(15):4145-4169

24. Zhang H, Nie J, Xiao R, Jin B, Dong C, Xiao G (2014) Catalytic co-pyrolysis of biomass and different plastics (polyethylene, polypropylene and polystyrene) to improve hydrocarbon yield in a fluidised bed reactor. Energy Fuels 28:1940-1947

25. Iftikar H, Zeeshan M, Iqbal S, Muneer B, Razzaq M (2019) Copyrolysis of sugarcane bagasse and polystyrene with ex-situ catalkytic bed of metal oxides/HZSM-5 with focus on liquid yield. Bioresour Technol. https://doi.org/10.1016/j.biortech.2019. 121647

26. Muneer B, Zeeshan M, Qaisar S, Razzaq M, Iftikar H (2019) Influence of in-situ and ex-situ HZSM-5 catalyst on co-pyrolysis of corn stalk and polystyrene with a focus on liquid yield and quality. J Clean Prod. https://doi.org/10.1016/j.jclepro.2019.117762

27. Kumar KP, Srinivas S (2020) Catalytic co-pyrolysis of biomass and plastics (polypropylene and polystyrene) using spent FCC catalyst. Energy Fuels 34:460-473

28. Dyer AC, Nahil MA, Williams PT (2020) Catalytic co-pyrolysis of biomass and waste plastics as a route to upgraded bio-oil. J Energy Inst 97:27-36

29. Iliopoulou EF, Stefanidis SD, Kalogiannis KG, Delimitis A, Lappas AA, Triantafyllidis KS (2012) Catalytic upgrading of biomass pyrolysis vapors using transition metal-modified ZSM-5 zeolite. Appl Catal B 127:281-290

30. Zheng Y, Wang F, Yang X, Huang Y, Liu C, Zheng Z, Gu J (2017) Study on aromatic production via the catalytic pyrolysis vapor upgrading of biomass using metal-loaded modified H-ZSM-5. J Anal Appl Pyrolysis 126:169-179

31. Zhao C, Jiang E, Chen A (2017) Volatile production from pyrolysis of cellulose, hemicellulose and lignin. J Energy Inst 90(6):902-913

32. Jaffar MM, Nahil MA, Williams PT (2020) Pyrolysis-catalytic hydrogenation of cellulose-hemicellulose-lignin and biomass agricultural wastes for synthetic natural gas production. J Anal Appl Pyrolysis. https://doi.org/10.1016/j.jaap.2019.104753 
33. Ahmed I, Nipattummakul N, Gupta A (2011) Characteristics of syngas from co-gasification of polyethylene and woodchips. Appl Energy 88(1):165-174

34. Burra KG, Gupta AK (2018) Synergistic effects in steam gasification of combined biomass and plastic waste mixtures. Appl Energy 211:230-236

35. Oyedun AO, Gebreegzaibher T, Ng DKS, Hui CW (2014) Mixed waste pyrolysis of biomass and plastics waste-a modelling approach to reduce energy usage. Energy 75:127-135

36. Lin YC, Huber GW (2009) The critical role of heterogeneous catalysis in lignocellulosic biomass conversion. Energy Environ Sci 2(1):68-80

37. Huber GW, Corma A (2007) Synergies between bio- and oil refineries for the production of fuels from biomass. Angew Chem Int Ed 46(38):7184-7201

38. Guedes RE, Luna AS, Torres AR (2018) Operating parameters for bio-oil production in biomass pyrolysis: a review. J Anal Appl Pyrolysis 129:134-149

39. Abu El-Rub Z, Bramer EA, Brem G (2004) Review of catalysts for tar elimination in biomass gasification processes. Ind Eng Chem Res 43(22):6911-6919

40. Wu C, Williams PT (2011) Nickel-based catalysts for tar reduction in biomass gasification. Biofuels 2:451-464

41. Veses A, Puértolas B, Callén MS, García T (2015) Catalytic upgrading of biomass derived pyrolysis vapors over metal-loaded ZSM-5 zeolites: effect of different metal cations on the bio-oil final properties. Microporous Mesoporous Mater 209:189-196

42. Che Q, Yang M, Wang X, Yang Q, Williams LR, Yang H, Zou J, Zeng K, Zhu Y, Chen Y, Chen H (2019) Influence of physicochemical properties of metal modified ZSM-5 catalyst on benzene, toluene and xylene production from biomass catalytic pyrolysis. Bioresour Technol 278:248-254

43. Zhang S, Zhang H, Liu X, Zhu S, Hu L, Zhang Q (2018) Upgrading of bio-oil from catalytic pyrolysis of pretreated rice husk over Fe-modified ZSM-5 zeolite catalyst. Fuel Process Technol 175:17-25

44. Williams PT, Bagri R (2004) hydrocarbon gases and oils from the recycling of polystyrene waste by catalytic pyrolysis. Int J Energy Res 28:31-44

45. Muhammad C, Onwudili JA, Williams PT (2015) Thermal degradation of real-world waste plastics and simulated mixed plastics in a two-stage pyrolysis-catalysis reactor for fuel production. Energy Fuels 29:2601-2609

46. Serrano DP, Aguado J, Escola JM (2012) Developing advanced catalysts for the conversion of polyolefinic waste plastics into fuels and chemicals. ACS Catal 2:1924-1941

47. Charoenwianguea P, Maihom T, Kongpracha P, Sirijaraensre J, Limtrakul J (2016) Adsorption and decarboxylation of furfural over H-ZSM-5 zeolite: a DFT study. RSC Adv 6:105888-105894

48. Liu R, Sarker M, Rahman MM, Li C, Chai M, Nishu CR, Scott NR (2020) Multi-scale complexities of solid acid catalysts in the catalytic fast pyrolysis of biomass for bio-oil production-a review. Prog Energy Combust Sci. https://doi.org/10.1016/j.pecs. 2020.100852

49. Primo A, Garcia H (2014) Zeolites as catalysts in oil refining. Chem Soc Rev 43(22):7548-7561

50. Jae J, Tompsett GA, Foster AJ, Hammond KD, Auerbach SM, Lobo RF, Huber GW (2011) Investigation into the shape selectivity of zeolite catalysts for biomass conversion. J Catal 279(2):257-268

51. Bhatia S (1989) Zeolite catalysts: principles and applications. CRC Press, Boca Raton

52. Lee HW, Cha JS, Park YK (2018) Catalytic co-pyrolysis of Kraft lignin with refuse derived fuels using Ni-loaded ZSM-5 type catalysts. Catalysts 8:506

53. Rezaei PS, Shafaghat H, Daud WMAW (2014) Production of green aromatics and olefins by catalytic cracking of oxygenate compounds derived from biomass pyrolysis: a review. Appl Catal A 469:490-511

54. Yung MM, Starace AK, Mukarakate C, Crow AM, Leshnov MA, Magrini KA (2016) Biomass catalytic pyrolysis on $\mathrm{Ni} /$ ZSM-5: effect of nickel pretreatment and loading. Energy Fuels 30(7):5259-5268

55. Hunger M (2010) Catalytically active sites: generation and characterization. In: Cejka J, Corma A, Zones S (eds) Zeolites and catalysis: synthesis, reactions and applications. Wiley, Weinheim, pp 493-546

56. Shigeishi RA, Chiche BH, Fajula F (2001) CO adsorption on superacid sites on dealuminated mazzite. Microporous Mesoporous Mater 43(2):211-226

57. Cheng YT, Jae J, Shi J, Fan W, Huber GW (2012) Production of renewable aromatic compounds by catalytic fast pyrolysis of lignocellulosic biomass with bifunctional Ga/ZSM-5 catalysts. Angew Chem 124(6):1416-1419

58. Cheng YT, Jae J, Shi J, Fan W, Huber GW (2012) Production of renewable aromatic compounds by catalytic fast pyrolysis of lignocellulosic biomass with bifunctional Ga/ZSM-5 catalysts. Angew Chem 51:1387-1390

59. Hocking MB (2005) Chapter 19 petrochemicals. Handbook of chemical technology and pollution control, 3rd edn. Academic Press, London, pp 637-668

60. Nexant Technical Report 2018-6 (2018) Styrene/Ethylbenzene. Nexant Corp., San Francisco

Publisher's Note Springer Nature remains neutral with regard to jurisdictional claims in published maps and institutional affiliations. 